\title{
Imagens visuais em livros didáticos de História
}

Tese de doutorado em Educação defendida em 2011 na FE-Unicamp Orientadora: Profa. Dra. Maria Carolina Bovério Galzerani
João Batista G. Bueno joaobgbueno@hotmail.com
$\mathcal{A}$ s imagens visuais - ou as chamadas "ilustraçôes"- presentes nos manuais didáticos têm sido lidas de diferentes maneiras, historicamente datadas, na relação direta com diferentes práticas pedagógicas e culturais. Contudo, de uma maneira geral, hoje as iconografias dos livros didáticos aparecem associadas a um texto escrito que procura criar uma afirmação verbal identificadora da informação não verbal. Para o saber editorial, na contemporaneidade, os textos escritos, quando associados à imagem visual, têm a função de limitar ou dirigir o ato de leitura para uma dada interpretaçáo sobre as iconografias. Em nossos estudos sobre os livros didáticos produzidos no Brasil, sobretudo, no período de 1970 a 2000, percebemos que esta forma escolar e editorial de apresentaçáo dos conteúdos foi sendo construída historicamente na relação com as culturas escolares e os diferentes saberes relacionados à produção e à recepção de veículos de informaçáo impressa. [Ver Fig. 1]

A imagem visual é entendida na contemporaneidade, também, como ilustração nos diferentes tipos de impressos. Schaeffer (1996), em seu livro "A imagem precária", apresenta o depoimento da fotógrafa Gisele Freund para explicar como os textos escritos têm poder para direcionar os sentidos de interpretação das imagens visuais em veículos de comunicação como jornais e revistas. Em suas palavras:

É assim que Gisele Freund denuncia a falta de "objetividade" da imagem fotográfica: "A objetividade da imagem náo passa de uma ilusão. As legendas que comentam podem mudar totalmente seu significado". E para demonstrar a exatidão de sua opinião, fornece vários exemplos obtidos de sua própria experiência jornalística. É interessante analisá-los de maneira mais detalhada: "Antes da guerra, a venda e compra de títulos da Bolsa de Paris aconteciam ao ar livre, sob as arcadas. Um dia, eu tirava uma série de fotos, tendo como alvo um agente de câmbio. Ora sorrindo, ora com expressão angustia$\mathrm{da}$, enxugando o rosto redondo, exortava as pessoas com amplos gestos. Mandei essas fotos a vários jornais ilustrados europeus sob o inofensivo título: Instantâneos da Bolsa de Paris. Algum tempo mais tarde, recebi recortes de um jornal belga, e qual não foi minha surpresa ao ver minhas fotos em uma manchete que dizia: Alta na Bolsa de Paris, as açôes alcançam preços fabulosos. Graças aos subtítulos ardilosos, minha inocente reportagem passava a ter 
o sentido de um acontecimento financeiro. Minha surpresa quase me sufocou quando vi, alguns dias mais tarde, as mesmas fotos em um jornal alemão, desta vez com o título Pânico na Bolsa de Paris, perdem-se fortunas, milhares de pessoas arruinadas. Minhas imagens ilustravam perfeitamente o desespero do vendedor e o pânico do espectador se arruinando. É evidente que cada jornal deu às minhas fotos um sentido diametralmente oposto, conforme sua intenções políticas". (1974: 73-74)

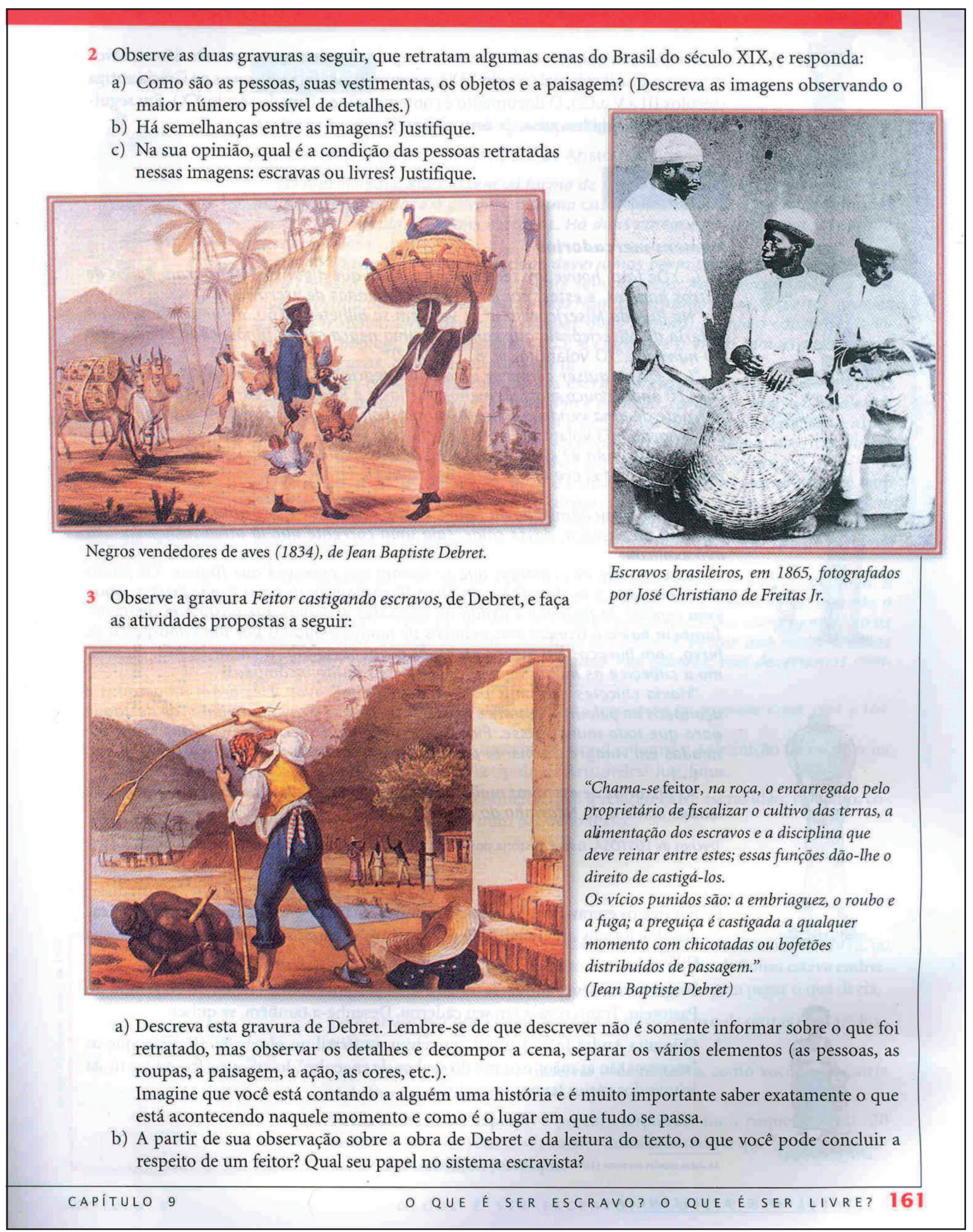

Figura 1 
Outros pesquisadores da atualidade procuram entender o papel das ilustraçóes enquadrando-as em diferentes categorias.

Para Oliveira (1998), as ilustraçóes podem ser divididas em dois tipos: como narrativas e como persuasivas. $\mathrm{Na}$ primeira categoria o leitor reconhece que as representações da imagem visual se comprometem com a concepção de narração; neste sentido, imagina que a cena observada apresenta um tempo anterior e um tempo posterior a esta. A partir desta compreensão, pode, então, construir uma narrativa partindo da representação imagética. Na segunda categoria a imagem visual apresenta a noção de persuasão e convencimento. Em grande parte das vezes, os editores de materiais impressos, quando lançam mão dessa forma de ilustração, na contemporaneidade, procuram limitar os sentidos de leitura, esperando induzir o leitor a um determinado comportamento ou ação. Esperam, dessa forma, direcionar a interpretação, de modo que esta seja a mais próxima possível das visóes do produtor da imagem. Esse tipo de ilustração é muito utilizado nos meios publicitários para a divulgação de propagandas.

Já Graça Paulino (1995) propóe enquadrar as ilustraçóes em mais um tipo de categoria. Para essa autora, as ilustraçóes podem ser argumentativas. Isto acontece quando as imagens visuais enriquecem e acrescentam mais informaçóes ao que foi exposto pelo texto escrito associado.

A autora Jean-Marie Charon (1999), por sua vez, acredita que essa mesma categoria possa ser reconhecida quando a imagem visual informa o leitor sobre determinado contexto, apresentando circunstâncias diferentes, referentes aos protagonistas ou às açóes representadas. Para Charon, este tipo de ilustração provoca diversos sentimentos no leitor, pois apela para algum tipo de representaçẫo que desperta as suas sensibilidades.

O saber editorial na atualidade, igualmente, utiliza as imagens visuais como sinal de pontuação, colocando-as estrategicamente em diferentes posiçôes no espaço das páginas impressas, com o objetivo de fazer a separação de trechos dos textos escritos.

Quando analisamos as ilustraçôes dos livros didáticos, percebemos, entretanto, que essas classificaçôes não dão conta da pluralidade de formas de interpretação que historicamente as ima- gens visuais sugerem aos leitores. Por isso, muitas vezes, é possível reconhecer que uma mesma ilustração pode apresentar características de uma ou mais dessas categorias. Portanto, a construção de análises das ilustraçóes dos livros didáticos não pode limitar-se à utilização dessas formas de classificação, porque existe sempre a possibilidade de o leitor vinculá-las às suas experiências vividas, de fazer rememoraçóes a partir delas, de criar um saber ou experimentar determinados sentimentos. $\mathrm{Ou}$, ainda, o leitor, ao observar uma iconografia, pode identificar e criar novas imagens mentais.

De acordo com Jacques Almont, (2001: 127) o ato de leitura de imagens permite que o leitor exercite sua imaginação e estimule suas faculdades criativas.

Se a imagem é feita para ser olhada, para satisfazer (parcialmente) a pulsão escópica, deve proporcionar um prazer de tipo particular. A essa observação respondeu um texto importante, A câmara clara, de Roland Barthes (1980), que teoriza a relaçáo do espectador com a imagem fotográfica. Barthes opóe duas maneiras de apreender uma (mesma) fotografia, o que chama de foto do fotógrafo e de foto do espectador. A primeira emprega a informação contida na foto, sinais objetivos, um campo codificado intencionalmente, o conjunto dependendo do que chama de studium; a segunda emprega o acaso, as associações subjetivas, e descobre na foto um objeto parcial de desejo, não-codificado, não intencional, $\mathrm{o}$ punctum.

Por um longo período em nosso país, que se estende desde a produção dos primeiros impressos no século XIX até os nossos dias, as imagens visuais têm sido percebidas como meios de comunicação que estão, hierarquicamente, submissos aos textos verbais. Contudo, na contemporaneidade tal imagem deixou de ser consensual e vem sendo problematizada por representantes do meio acadêmico e escolar brasileiro, sobretudo das áreas do ensino História, ensino de Artes e Comunicação e Expressão.[1]

Segundo Bittencourt, (2009: 360) o uso de imagens iconográficas tornou-se recorrente no 
ensino de História em nosso país, tendo um crescimento significativo a partir da segunda metade do século XX. Mais especificamente, desde a década de 1980, as imagens iconográficas começaram deixar de serem vistas apenas como simples "ilustraçâo" e passaram a ser consideradas expressôes (produtos e instituidoras) da sociedade que a gerou (PROPOSTA CURRICULAR PARA O ENSINO DE HISTÓRIA, CENP, SEE/ SP,1986). Bittencourt (2001: 135) afirma, ainda, que nos anos finais da década de 1980 os currículos oficiais passaram a valorizar a produçáo de materiais didáticos que priorizavam a apresentação de atividades voltadas para a reflexão, relativa às questōes tais como: “(...) Diversidade cultural, os problemas de identidade social e (....) as formas de apreensão e domínio das informaçôes impostas pelos jovens formados pela mídia”.

Embora seja, ainda hoje, tendência usual os manuais didáticos apresentarem textos escritos, e, por vezes, algumas imagens visuais geradas com objetivos pedagógicos, é comum encontrarmos, nestes materiais, muitas imagens visuais e textos escritos que não foram produzidos, na sua origem, com fins didáticos. Nesse sentido, estas fontes escritas e iconográficas podem estabelecer relações de complementação ou de tensão com os textos explicativos, com as legendas, ou, então, com os enunciados dos exercícios.

As composiçóes visuais das páginas dos livros didáticos, resultantes das diagramaçóes dos textos escritos com as iconografias, têm por objetivo, como já foi salientado, orientar uma determinada forma de leitura, que, no caso, é destina$\mathrm{da}$ aos alunos e aos professores. Isto é, os produtores dos livros procuram propor um "contrato de leitura" (BATISTA, 1999: 37) que deve ser aceito pelos leitores. Nessa linha de pensamento, a forma escolar instituiu e vem instituindo, historicamente, determinadas maneiras de composições gráficas, de imagens e textos escritos, bem como determinadas concepçóes de leitura- tais como, por exemplo, que o leitor fizesse e faça o reconhecimento das imagens visuais, relacionando-as ao que foi apresentado pelo texto escrito ou pela legenda.

É consenso, hoje, entre os pesquisadores, que as imagens visuais são portadoras de significados, e que o leitor pode relacioná-las com diferen- tes tipos de informaçóes, de saberes, dependendo da sua experiência de vida, de sua cultura. Por isso, para que as iconografias dos livros didáticos de história sejam consideradas como documentos históricos, tanto o professor como os alunos têm que acreditar que as imagens que estáo vendo constituem documentos históricos. Entre as várias possibilidades de abordagens, é importante compreendermos que as iconografias são selecionadas por autores, ilustradores e editores dos livros didáticos para trabalhar diversos temas históricos: podem representar, entre outras possibilidades, um ou mais objetos do passado ou paisagens; o meio urbano ou rural; diferentes objetos arquitetônicos ou patrimônios históricos, e também, retratos de pessoas comuns ou personalidades que se destacaram nas várias áreas que compóem a sociedade. São, portanto, reproduçôes impressas de outras imagens de origens, suportes e técnicas diferentes. Ou seja, são "reproduçôes", muitas vezes alteradas, de pinturas e de fotografias, ou, então, são desenhos produzidos por ilustradores. Além disso, é importante ressaltar que as iconografias que originaram as reproduçôes impressas dos livros didáticos foram produzidas por um autor, num determinado tempo e espaço e com uma dada intencionalidade. $\mathrm{Na}$ época de sua produção, poderiam proporcionar diferentes formas de interpretação, as quais, talvez, não sejam reconhecíveis pelo leitor contemporâneo. [Ver Fig. 2]

Os autores e editores dos livros didáticos, lançados no mercado após a divulgação dos $\mathrm{Pa}$ râmetros Curriculares Nacionais de Ensino de História (PCN) para os níveis fundamental e médio, nos anos de 1997 e de 1998, procuraram justificar as propostas de leitura de iconografias, fundamentalmente, pelos estudos teóricos elaborados pela academia. No entanto, concordamos com Gatti (1998: 18), quando este autor destaca que:

(...) a partir dos relatos feitos pelos autores e editores de diversas coleçôes didáticas, foi possível perceber que a constituiçáo dos conteúdos disciplinares, expressos nos livros didáticos, não era a transposição dos saberes produzidos na pesquisa científica, mas, sim, resultado de um leque amplo de fatores, tais como: as novidades produzidas 


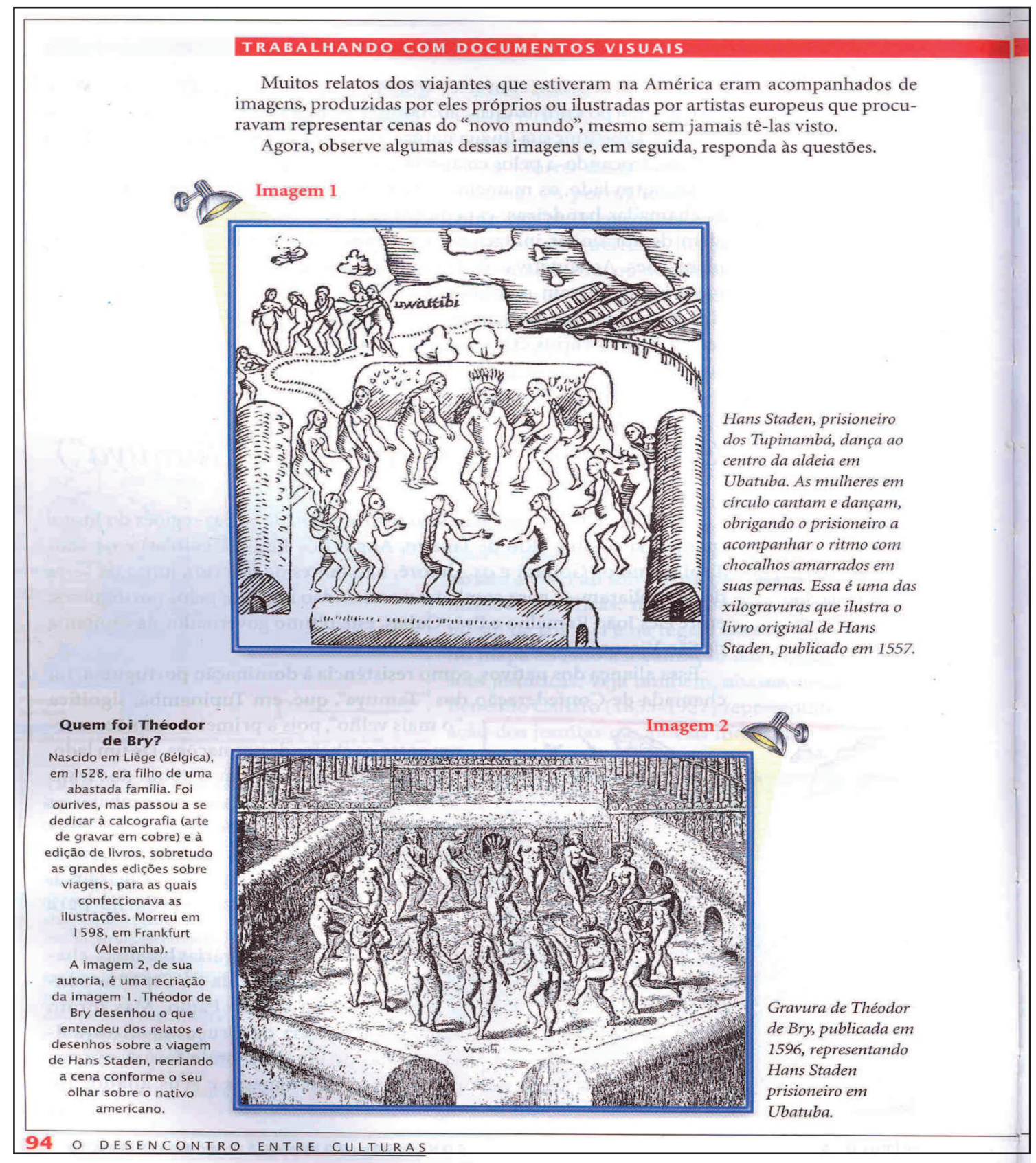

Figura 2

no âmbito das ciências, que são selecionadas conforme as opçôes teórico-metodológicas dos autores e, por vezes, dos editores; as mudanças curriculares e programáticas provenientes dos diversos órgãos que legislam sobre a educaçáo escolar; a sociedade civil, especialmente a mídia que por vezes conduz o aparecimento ou a valorização de certas temáticas em detrimento de outras.

Ao analisarmos as propostas de leitura de imagens visuais, impressas nos livros didáticos brasileiros editados a partir da década de 1970 até a contemporaneidade, pudemos compreender que estas podem revelar diferentes tipos de abordagens, se comparadas às metodologias propostas pelos estudos acadêmicos. Neste sentido, as metodologias apresentadas nos manuais didáticos representavam o resultado dos embates entre os saberes acadêmicos e editoriais com os saberes produzidos pelos docentes na relação com os discentes. As propostas de leituras impressas nos livros 
revelam, também, como os autores, ilustradores e editores, posicionaram-se frente às concepçóes histórico-pedagógicas vigentes nos diferentes períodos, e como se adequaram às exigências da legislação educacional, impostas pelo Estado.

Os professores de História da atualidade enfrentam várias dificuldades e embaraços metodológicos quando tentam ministrar aulas utilizando as imagens visuais presentes nos livros didáticos na educação básica, tanto pública como privada. As raízes dessas dificuldades relacionamse, principalmente, às permanências, nas culturas escolares, da valorização do uso de documentos escritos como fonte privilegiada de produção de conhecimentos históricos.

Entendemos que o livro didático é um material atravessado por dimensóes complexas das culturas escolares e, ao mesmo tempo, das culturas extra-escolares. Ao confrontar as diferentes propostas de leitura de imagens visuais, impressas nos livros didáticos, percebemos como a produção dos saberes docentes e escolares participam da formação das tendências dominantes, que priorizam, atualmente, determinadas metodologias de leitura de imagens em detrimento de outras.

Vińao Frago (1993) entende que estas práticas são estabelecidas pelas culturas das escolas, pois são legitimadas pelos saberes dos alunos e dos professores. Muitas vezes, esses personagens acreditam que as instruçôes trazidas nos livros didáticos são portadoras dos conteúdos que devem ser ensinados e aprendidos, e, por isso, as atividades didáticas devem ser realizadas seguindo as formas que aparecem impressas nos livros. Além disso, o cumprimento das atividades propostas pelos livros faz parte de imposições estabelecidas por normas internas das instituiçóes de ensino e/ou externas - vindas do Estado e da sociedade.

Em relação às metodologias de leitura de imagens visuais que passaram a ser apresentadas nos livros didáticos de História, acreditamos que estas se inseriram nas culturas escolares dentro de um processo de amálgama de saberes. São conhecimentos que foram instituídos pelas sugestóes indicadas nos livros didáticos, mas sempre na relaçáo com os saberes produzidos por professores e alunos.

De acordo com os pensamentos de Julia, (2001: 9) poderemos, então, compreender que as sugestôes de leituras de imagens visuais, propostas nos livros didáticos, não são, necessariamente, seguidas como normas rígidas por professores e alunos. Estes personagens que compõem as instituições escolares podem traduzir essas regras em fazeres outros, podem eliminar diretrizes que considerem inadequadas ou selecionar determinadas atividades em detrimento de outras. (VIDAL, 2005: 29)

Para Julia (2001, p. 10), as formas de leitura de imagens visuais, utilizadas pelos professores, respeitam o "conjunto de normas que definem conhecimentos a ensinar (...) de práticas que permitem a transmissão desses conhecimentos e a incorporação desses comportamentos”. E, por isso, elas podem ser "inventivas". São produtoras de novas configuraçôes de conhecimento, derivadas dos saberes que foram produzidos pela academia, mas resignificadas no interior das tensões vividas na instituição escolar. Estas são, também, formas de leitura que partem das experiências culturais mais amplas, vividas pelos professores e alunos, tanto no interior da sala de aula como fora desta. Sáo formas de leitura que têm historicidade e que podem variar no tempo e no espaço, de escola para escola, de turma de alunos para turma de alunos.

Vidal (2005) assegura, por sua vez, que é possível entender, também, que as escolhas relativas à forma de ler os textos verbais e não verbais podem expressar diferenças sociais sobre as questôes de gênero, geraçáo, etnia, classe ou grupo social dos indivíduos. Para essa autora, é a partir do reconhecimento dessas diferenças que os novos saberes vão se constituindo nas escolas.

Por isso, as editoras, na contemporaneidade brasileira, utilizam as práticas do pré-teste do livro didático, antes de sua divulgação no mercado. Ou então, contratam professores da educação básica para analisarem os livros didáticos. Estes profissionais analisam o formato dos textos e das imagens e apresentam opinióes sobre as metodologias de análise textual escrita e iconográfica que o livro didático apresenta. Nesta oportunidade, os editores podem acatar as sugestóes desses consultores, sendo adicionadas ou retiradas atividades que se encontram nos livros. É nesse momento, também, que as propostas de leitura são ampliadas, de acordo com os saberes construídos 
nas práticas de sala de aula.

Aliado ao conceito de cultura escolar é importante enfatizar que ao estudarmos as permanências e mudanças das propostas de leitura de imagens visuais impressas nos livros didáticos, necessitamos levar em conta as contribuições do conceito de "forma escolar" produzidas por Guy Vincent, Bernard Lahire e Daniel Thin (2001).

A partir das concepçôes de Vincent (et. al.) foi possível reconhecermos que as propostas de leituras de imagens visuais impressas, apresentadas nos livros didáticos, constituem saberes formalizados. Esses saberes trazem efeitos duráveis de socialização sobre os alunos e professores e relacionam-se às práticas de leituras de imagens visuais. Além disso, são conhecimentos que disseminam e instituem uma determinada forma de aprendizagem que extrapola o campo escolar.

Para Vincent et. al. (2001: 28-29), a escola é o lugar onde as:

[...] relações sociais de aprendizagem estão ligadas à constituição de saberes escriturais formalizados, saberes objetivados, delimitados, codificados, concernentes tanto ao que é ensinado quanto à maneira de ensinar, tanto às práticas dos alunos quanto à prática dos mestres. A pedagogia (no sentido restrito da palavra) se articula a um modelo explícito, objetivado e fixo de saber a transmitir". [...]"Historicamente, a pedagogização, a escolarização das relações sociais de aprendizagem é indissociável de uma escrituralização-codificação dos saberes e das práticas" [...] "O modo de socialização escolar é, portanto, indissociável da natureza escritural dos saberes a transmitir".

Ao constatar essas relaçôes, no diálogo com os livros didáticos, podemos concluir que existem elementos da forma escolar que contribuem para a estruturação destes manuais. Isto se dá, principalmente, nas formas de apresentação dos conteúdos e das atividades.

Para Vincent et. al. (2001: 14), a maneira como sáo apresentados os conceitos das diferentes disciplinas nos livros didáticos são formas escolares. Por isso, as disposiçóes que regem a apresenta- ção dos textos escritos na relação com as imagens visuais, a maneira como são desenvolvidas e ordenadas as atividades e os exercícios destinados aos alunos, assim como as instruçóes didáticas dos manuais dos professores, que compóem os livros didáticos, são todas elas formas escolares. É possível, portanto, através do estudo das suas recorrências, compreendermos como pequenas mudanças vão sendo produzidas nos manuais didáticos ao longo dos anos, e como elas podem alterar os saberes e fazeres escolares.

\section{Para Vincent, et. al. (2001: 9-10):}

[...] falar de forma escolar é, portanto, pesquisar o que faz a unidade de uma configuração histórica particular, surgida em determinadas formaçôes sociais, em certa época, e, ao mesmo tempo em que outras transformaçóes, através de um procedimento tanto descritivo quanto "compreensivo". (...) "uma teoria da forma escolar permite [...] pensar a mudança. (...) o que se poderia chamar a recorrência através das modificaçóes".

A percepção de que podem existir pequenas mudanças no interior das permanências, nos manuais didáticos, já foi apontada tanto por Chervel (1990) como por Julia (2001). Esses autores compreenderam que as mudanças nos livros didáticos ocorrem de maneira sutil e estas têm sido introduzidas lentamente nas práticas escolares. É a partir da identificação analítica dessas pequenas alteraçóes nestes materiais didáticos que podemos compreender indícios de alteraçóes político-culturais mais profundas, historicamente localizadas.

Destacamos que, historicamente, se tem valorizado muito mais o texto escrito do que texto iconográfico em práticas pedagógicas de leitura, também em nosso país. Pois bem, pode-se afirmar que se trata, tal prática, de uma dada forma escolar, a qual, por sua vez, tem-se constituído num importante fator para compreendermos a permanência da dificuldade do desenvolvimento de novas metodologias de leituras de imagens visuais, no dia-a-dia da sala de aula. 
Vincent, et. al. (2001: 15-17) localiza a invenção da forma escolar nos séculos XVI e XVII. A partir desse período foram sendo instituídas formas de "transmitir saberes e o saber fazer". Instituíramse métodos pedagógicos que valorizaram algumas práticas, em detrimento de outras. Neste contexto, as metodologias vencedoras priorizaram a relação escritural na sociedade como forma de exercício de poder.

Já em nossa sociedade contemporânea, a interpretação das imagens visuais ganhou um status semelhante à habilidade de dominar a escrita, constituindo-se como necessidade que se estabeleceu para a maioria da população. Foi a partir de meados do século XX que começaram a serem valorizados os estudos e a estruturação de novas metodologias que procuravam focalizar a leitura de imagem iconográfica como prática que deve ser desenvolvida nas escolas. Surgiram, então, teorias que defendiam a alfabetização visual (DONDIS, 2000: 8), expandindo a idéia de alfabetização, que passa do domínio da escrita para o domínio e interpretação de todos os signos de informação.

Neste artigo sugerimos que vivemos, nos dias de hoje, um movimento de embates entre as propostas metodológicas que procuram estabelecer formas "corretas" de uso de imagens na instituição escolar. Isto porque a instituição de metodologias de análise de imagens visuais são formas de exercícios de poder, que buscam, em meio a uma batalha de percepçóes, instituir "saberes objetivados, explícitos, sistematizados e codificados". (VINCENT et.al, 2001: 18)

\section{Nota}

1 - No caso da área do Ensino de História ver: BITTENCOURT, Circe. Livros didáticos entre textos e imagens In: BITTENCOURT,Circe (Org.). O Saber Histórico na sala de aula, São Paulo, Contexto, 2001. ZAMBONI, Ernesta Representações e Linguagens no ensino de História In: Revista Brasileira de História. ANPUH/ Humanitas Publicações, vol. 18, $\mathrm{n}^{\circ}$ 36, 1998. MAUAD, Ana Maria. As imagens que educam e instruem: usos e funções das ilustrações nos livros didáticos de história. In: DIAS, Margarida e STAMATTO, Inês. O Livro didático de história: políticas, educacionais, pesquisas e ensino, Natal:
Ed. UFRN, 2007. PURIFICAÇÃO, Ana Teresa de Souza e Castro da. (Re)criando interpretações sobre a Independência do Brasil: um estudo das mediações entre memória e história nos livros didáticos. (Dissertação de mestrado). São Paulo: FFLCH/USP, 2002. COSTA, Warley da. A leitura das imagens da escravidão nos livros didáticos de história. Anais $15^{\circ}$ Congresso de leitura do Brasil, 2008; OLIM,Bárbara Barros de. Imagens em livros didáticos de História das séries iniciais: uma análise comparativa e avaliadora. Revista Outros Tempos. Volume 7, número 10, dezembro de 2010; BUENO, João Batista Gonçalves. Representações Iconográficas em livros didáticos de História. Dissertação de Mestrado FE- Unicamp 2003 (entre outros). No caso da área de Comunicação e Expressão, destacam-se estudos de BELMIRO, Celia Abicalil. A imagem e suas formas de visualidade nos livros didáticos de Português, Educ. Soc. vol. 21, nº.72 Campinas, Aug. 2000; Imagens e práticas intertextuais em processos educativos(co-autoria com Delfim Afonso Jr. E Armando Martins de Barros). In: VERSIANI, Zélia et.al.(org). Letramento literário: espaços, suportes e interfaces - o jogo do Livro IV. Belo Horizonte: Autêntica/CEALE/FaE/ UFMG.2003, p. 209-224; Uma educação estética nos livros didáticos de Português, In: ROJO \& BATISTA(orgs). Livro didático de língua portuguesa, letramento e cultura da escrita. Campinas, SP: Mercado das Letras,2003, p. 2999-320; Texto literário e imagens, nas mediações escolares. In: PAULINO, Graça \& CASSON, Rildo(org) Leitura literária:a mediação escolar. Belo Horizonte: Faculdade de Letras da UFMG, 2004, p. 147-154. BRAGATO, Solange. A Leitura do texto literário e da imagem no livro didático do ensino fundamental. Dissertação de Mestrado pela Universidade Estadual de Maringá 2005, entre outros. No caso da área de Artes destacam-se as seguintes publicações: OLIVEIRA, Jô; GARCEZ, Lucília. Explicando a arte: uma iniciação para entender e apreciar as artes visuais. 3. ed. Rio de Janeiro: Ediouro, 2002. LANIER, Vincent. Devolvendo arte à arte-educação. In. BARBOSA, Ana Mae Tavares (org.). Arte-educação: leitura no subsolo. 3. ed. São Paulo: Cortez, 2001. JOLY, Martine. Introdução à análise da imagem. 6. ed. 
Trad. Marina Appenzeller.Campinas, São Paulo: Papirus, 2003. MAGALHÃES, Ana Del Tabor Vasconcelos. Ensino de arte: perspectivas com base na prática de ensino. In. BARBOSA, Ana Mae Tavares (org.). Inquietações e mudanças no ensino da arte. São Paulo: Cortez, 2002, dentre outros.

\section{REFERÊNCIAS BIBLIOGRÁFICAS}

AUMONT, Jacques. A Imagem. Campinas, SP: Papirus, 2001, p.127.

BATISTA, Antônio Augusto G. Um Objeto Variável e Instável: Textos, Impressos e Livros Didáticos. Belo Horizonte. UFMG, 1999.p.37.

BITTENCOURT, C. M. F. "Livros didáticos entre textos e imagens". In: O Saber Histórico na Sala de Aula, SP: Ed. Contexto, 2001, p.60-90.

Ensino de História: Fundamentos $e$ Métodos. São Paulo: Cortez, 2009.

CHARON, Jean-Marie. La Presse Magazine. Paris: La Decouverte, 1999.

CHERVEL, André. "História das disciplinas escolares: reflexões sobre um campo de pesquisa". Teoria \& Educação, 2, 1990, p. 177-229.

DONDIS, D. A Sintaxe da Linguagem Visual. São Paulo: Martins Fontes, 1991( La sintaxis de la imagen. Barcelona: Editorial Gustavo Gilli, 2000).

FREUND, Gisele. Photographie et Société. Paris: Seuil, 1974.

GATTI Jr., Décio. "Livro didático e ensino de
História: dos anos sessenta aos nossos dias". PUC/SP, 1998. (tese de Doutorado em Educação: História, Política, Sociedade).

JULIA, Dominique. "A cultura escolar como objeto histórico". Revista Brasileira de História da Educação, n. 1, 2001, p. 9-44.

OLIVEIRA, Rui de. "A arte de contar histórias por imagens". Presença Pedagógica. Vol.4,19, jan/fev. 1998, p. 60-74.

PAULINO, Graça. WALTY, Ivete, CURY, Maria Zilda. Intertextualidades: Teoria e Prática. Belo Horizonte: Ed. Lê, 1995.

PARÂMETROS CURRICULARES NACIONAIS. Ensino Fundamental e Médio - Área de História. Brasília/DF: MEC, 1997 e 1998.

SCHAEFFER, J.M. A Imagem Precária: Sobre o Dispositivo Fotográfico. Campinas: Ed. Papirus, 1996.

PROPOSTA CURRICULAR PARA O ENSINO DE HISTÓRIA - $1^{\circ}$. GRAU, CENP, SEE/ SP, 1986.

VIDAL, Diana G. Culturas Escolares: Estudo Sobre Práticas de Leitura e Escrita na Escola Pública Primária (Brasil e França, no final do século XIX). Campinas - SP: Autores Associados, 2005. VINCENT,Guy; LAHIRE,Bernard \& THIN, Daniel. "Sobre a história e a teoria da forma escolar". Educação em Revista, jun., p. 7-48.

VIÑAO FRAGO, Antonio. Alfabetização na Sociedade e na História. Porto Alegre, Artes Médicas, 1993. 